\title{
UJI KEKERASAN RESIN KOMPOSIT AKTIVASI SINAR DENGAN BERBAGAI JARAK PENYINARAN
}

\author{
${ }^{1}$ Jimmy Allorerung \\ ${ }^{2}$ P. S. Anindita \\ ${ }^{2}$ Paulina N. Gunawan
}

\author{
${ }^{1}$ Kandidat Skripsi Program Studi Pendidikan Dokter Gigi Fakultas Kedokteran \\ ${ }^{2}$ Program Studi Pendidikan Dokter Gigi Universitas Sam Ratulangi \\ Email: jiro_bhoover16@yahoo.com
}

\begin{abstract}
Composite resin is a dental material which is used to fix the caries teeth because it have good esthetic and hardness. Visible light cured (VLC) composite resin hac better polymerization than chemical reaction composite resin. However, it does not have any abutment, therefore, the distance between light source and the composite surface is mostly ignored by the operator. Lightning process is very important to obtained good polymerization, so that the composite has enough hardness to hold back human masticate pressure. Composite which does not have enough hardness will be easily cracked. This study aimed to find out the correct distance of polymerization so that the composite resin has enough hardness to hold back human masticate pressure. This study used a post-test only design group and was conducted at the Laboratory of Metalurgy University of Sam Ratulangi. There were 27 samples of nanohybrid composite resin obtained by using a purposive sampling method. The measurement used was the Vickers method and micro Vickers hardness tester. The results showed that the group that had the highest hardness value was the first group with a lightning distance of $0 \mathrm{~mm}$ or light source touching composite resin surface, the value of hardness was $841.49 \mathrm{~N} / \mathrm{mm}^{2}$. This value step by step decreased because the lightning distance increased, so that the lowest hardness value is $290,95 \mathrm{~N} / \mathrm{mm}^{2}$ which on ninth group. Conclusion: The lightning distance of nanohybrid composite resin which could hold back the maximum human masticate pressure was on distance 0-6 $\mathrm{mm}$.
\end{abstract}

Keyword : distance of lightning, nanohybrid composite resin, hardness value.

\begin{abstract}
Abstrak: Resin komposit merupakan bahan tumpatan yang sering digunakan dalam kedokteran gigi karena memiliki nilai estetis serta kekerasan yang baik. Resin komposit aktivasi sinar berpolimerisasi lebih baik daripada resin komposit aktivasi kimia, tetapi alat visible light cured (VLC) yang digunakan tidak memiliki dudukan sehingga jarak antara sumber sinar dengan permukaan komposit saat penyinaran sering diabaikan. Proses penyinaran sangat penting agar terjadi polimerisasi yang baik sehingga komposit memiliki kekerasan yang cukup untuk menahan tekanan kunyah manusia. Kekerasan yang tidak cukup dapat menyebabkan komposit mengalami cracking atau pecahnya tumpatan didalam mulut. Tujuan penelitian ini untuk mengetahui jarak penyinaran yang tepat agar resin komposit memiliki kekerasan yang cukup untuk menahan tekanan kunyah manusia. Metode penelitian yang digunakan adalah metode post-test only design group yang diukur pada resin komposit jenis nanohibrid dan dilakukan di Laboratorium Metalurgi Jurusan Teknik Mesin Universitas Sam Ratulangi, dengan sampel sebanyak 27 sampel. Pengambilan sampel dilakukan dengan metode purposive sampling dan pengukuran kekerasan komposit menggunakan metode Vickers dan alat micro vickers hardness tester. Hasil penelitian menunjukan bahwa kelompok yang memiliki nilai kekerasan tertinggi terdapat pada kelompok pertama dengan jarak penyinaran $0 \mathrm{~mm}$ atau sumber sinar menyentuh permukaan komposit dengan nilai kekerasan
\end{abstract}


$841,49 \mathrm{~N} / \mathrm{mm}^{2}$. Nilai kekerasan ini secara bertahap menurun seiring dengan bertambah jauh jarak penyinaran, sehingga nilai kekerasan paling rendah terdapat pada kelompok penyinaran $8 \mathrm{~mm}$ yaitu 230,95 N/mm². Kesimpulan dari penelitian ini yaitu jarak penyinaran terhadap resin komposit jenis nanohibrid sehingga resin komposit memiliki kekerasan yang cukup untuk menahan tekanan kunyah maksimal manusia berkisar pada jarak 0-6 mm.

Kata kunci : jarak penyinaran, resin komposit nanohibrid, nilai kekerasan

Penampilan merupakan hal yang dijaga kebanyakan orang yang hidup di zaman sekarang. Satu dari banyak cara yang dapat dilakukan untuk menjaga penampilan yaitu dengan memperbaiki gigi yang sudah mengalami karies atau gigi berlubang dengan cara menumpat gigi. Menumpat gigi berlubang bukan hanya untuk kepentingan estetik namun tumpatan dapat digunakan sebagai cara sementara jika penderita mengalami suasana mulut yang sakit atau terganggu terhadap rangsangan panas, dingin, manis, namun menjadi pengganti yang buruk bagi email yang tidak mengalami cedera. ${ }^{1}$

Dalam kedokteran gigi, bahan yang biasanya digunakan sebagai bahan tumpatan antara lain amalgam, Glass Ionomer Cement (GIC), dan resin komposit. Masing-masing bahan tersebut memiliki keuntungan dan kerugian, baik dari segi estetik, kemampuan menahan tekanan dan cara manipulasi bahan. Resin komposit lebih sering digunakan karena resin komposit merupakan bahan tumpatan yang memiliki warna yang sama dengan gigi asli sehingga memiliki nilai estetik yang baik. $^{2}$

Resin komposit dapat diaktifkan dengan dua cara, yaitu diaktifkan secara kimia (self cured) dan diaktifkan dengan bantuan Visible Light Cure (VLC) atau sinar tampak. Resin komposit yang sering digunakan saat ini adalah resin komposit yang diaktifkan dengan bantuan $V L C$. Hal ini dikarenakan dengan adanya bantuan VLC resin komposit dapat berpolimerisasi dengan baik hingga ketebalan $2 \mathrm{~mm}$ dengan waktu penyinaran 60 detik dan panjang gelombang VLC 460-485 nm. Kekurangan yang dimiliki alat VLC yaitu tidak memiliki dudukan yang membantu operator untuk menentukan jarak yang tepat pada proses penyinaran, sehingga operator sering mengabaikan jarak penyinaran saat menumpat gigi. ${ }^{3}$

Proses penyinaran pada resin komposit merupakan hal penting yang harus diperhatikan saat proses penumpatan. Hal ini dikarenakan proses penyinaran yang kurang tepat menyebabkan polimerasi yang tidak sempurna sehingga kekerasan dari resin komposit yang dihasilkan tidak maksimal. Kekerasan yang tidak maksimal dapat mengakibatkan resin komposit tidak mampu untuk menahan tekanan yang dihasilkan saat manusia melakukan pengunyahan sehingga dapat mengalami cracking (pecah) dan tumpatan bisa terlepas dari gigi. ${ }^{4,5}$

Terjadinya cracking dan lepasnya tumpatan merugikan pasien dan dokter gigi. Pasien dirugikan dari segi materi karena harus kembali ke dokter gigi untuk memperbaiki tumpatan yang rusak sedangkan dokter gigi sebagai operator yang harus bekerja lagi untuk memperbaiki tumpatan yang seharusnya diperbaiki dalam jangka waktu yang lebih lama. Penelitian ini bertujuan untuk mendapatkan jarak penyinaran yang tepat agar resin komposit memiliki kekerasan cukup untuk menahan tekanan kunyah.

\section{BAHAN DAN METODE PENELITIAN}

Penelitian ini menggunakan metode deskriptif dengan posttest only design group. Penelitian dilaksanakan di laboratorium Program Studi Pendidikan Dokter Gigi untuk pembuatan sampel penelitian dan laboratorium Jurusan Teknik Mesin Fakultas Teknik Universitas Sam Ratulangi untuk pengukuran kekerasan sampel. Sampel yang digunakan pada penelitian ini ialah resin komposit nanohybrid sebanyak 27 sampel. Variabel 
penelitian ialah kekerasan resin komposit dan jarak penyinaran

Alat yang digunakan dalam penelitian yaitu sinar tampak (visible light curing), micro vickers hardness tester, silet, alat tulis menulis, masker, sarung tangan, glass plate, petridish, plastic filling instrument, pinset, jangka sorong. Bahan yang dipakai dalam penelitian yaitu resin komposit jenis nano hibrid yang diaktifkan dengan sinar, vaselin, sedotan berbahan plastik dengan diameter $5 \mathrm{~mm}$, celluloid strip

Cetakan resin komposit dibuat dengan menggunakan sedotan berbahan plastik dengan diameter $5 \mathrm{~mm}$ dan tinggi $2 \mathrm{~mm}$, Vaselin dioleskan pada bagian dalam cetakan dan cetakan diletakan di atas glass plateyang sudah dilapisi celluloid strip, cetakan untuk resin komposit yang sudah ada dibagi dalam 9 kelompok perlakuan yaitu jarak penyinaran $0 \mathrm{~mm}, 1 \mathrm{~mm}, 2 \mathrm{~mm}$, dan $3 \mathrm{~mm}, 4 \mathrm{~mm}, 5 \mathrm{~mm}, 6 \mathrm{~mm}, 7 \mathrm{~mm}$, dan $8 \mathrm{~mm}$ dengan masing-masing kelompok perlakuan memiliki 3 sampel. Komposit dimasukkan ke dalam cetakan menggunakan plastic filling instrument dan cetakan ditahan dengan menggunakan pinset agar saat pemasukan komposit cetakan tidak bergerak, Sisi atas dari cetakan yang telah diisi komposit kemudian diratakan menggunakan spatula semen mulai dari kelompok pertama dengan jarak penyinaran $0 \mathrm{~mm}$ atau sinar menyentuh komposit kemudian disinar selama 60 detik dengan panjang gelombang $465 \mathrm{~nm}$, langkah ini dilakukan berurutan sampai dengan kelompok kesembilan, Komposit dikeluarkan dari cetakan kemudian letakkan di petridish sesuai dengan kelompok jarak penyinaran, sampel dibawa ke laboratorium teknik mesin untuk diukur kekerasannya dengan metode Vickers dan menggunakan alat micro Vickers hardness tester, hasil yang diperoleh dari alat micro Vickers hardness tester ke dalam tabel kerja yang telah disediakan. Data yang diperoleh disajikan dalam bentuk tabel menggunakan program komputer.

\section{HASIL PENELITIAN}

Tabel 1 memperlihatkan bahwa nilai kekerasan rata-rata yang paling tinggi dimiliki oleh resin komposit yang disinar dengan jarak $0 \mathrm{~mm}$ atau sumber sinar mengenai permukaan resin komposit dengan rata-rata nilai kekerasan mencapai $841,49 \mathrm{~N} / \mathrm{mm}^{2}$. Nilai kekerasan ini secara bertahap menurun seiring dengan bertambah jauh jarak penyinaran terhadap resin komposit, sehingga nilai rata-rata kekerasan paling rendah terdapat pada kelompok dengan jarak penyinaran $8 \mathrm{~mm}$ yaitu 230,95 N/mm².

Tabel 1. Hasil pengukuran nilai kekerasan ratarata resin komposit.

\begin{tabular}{ccc}
\hline No & $\begin{array}{c}\text { Jarak } \\
\text { Penyinaran } \\
(\mathrm{mm})\end{array}$ & $\begin{array}{c}\text { Rata-rata nilai } \\
\text { kekerasan } \\
\left(\mathrm{N} / \mathrm{mm}^{2}\right)\end{array}$ \\
\hline 1 & $0 \mathrm{~mm}$ & 841,49 \\
2 & $1 \mathrm{~mm}$ & 769,62 \\
3 & $2 \mathrm{~mm}$ & 720,62 \\
4 & $3 \mathrm{~mm}$ & 646,8 \\
5 & $4 \mathrm{~mm}$ & 538,34 \\
6 & $5 \mathrm{~mm}$ & 395,92 \\
7 & $6 \mathrm{~mm}$ & 332,87 \\
8 & $7 \mathrm{~mm}$ & 283,54 \\
9 & $8 \mathrm{~mm}$ & 230,95 \\
\hline
\end{tabular}

\section{BAHASAN}

Berdasarkan hasil uji kekerasan resin komposit (Tabel 1), kelompok yang memiliki nilai kekerasan paling tinggi dimiliki oleh resin komposit yang terdapat pada kelompok yang disinar dengan jarak 0 $\mathrm{mm}$ atau sumber sinar menyentuh permukaan resin komposit dengan nilai kekerasan rata-rata $841,49 \mathrm{~N} / \mathrm{mm}^{2}$. Hasil penelitian ini sejalan dengan yang dikemukakan oleh Ferracane di Departemen Bahan Kedokteran Gigi Universitas Sao Paulo Brazil tahun 2001 bahwa untuk mendapatkan polimerasi yang optimal, jarak sumber sinar harus mengenai permukaan komposit. Polimerasi yang baik dapat meningkatkan kekerasan dari resin komposit, faktor yang dapat memengaruhi polimerasi resin komposit antara lain intensitas cahaya, lama penyinaran, panjang gelombang alat, ketebalan resin komposit, jarak ujung light curing unit terhadap permukaan restorasi, dan 
komposisi dari bahan resin komposit tersebut. Saat proses curing menggunakan Visible Light Cure terjadi ikatan silang (cross-linked) pada resin komposit sehingga aktifator yang ada pada resin komposit bereaksi dengan fotoinisiator menyebabkan adanya induksi sinar VLC yang menyebabkan terjadinya polimerisasi antara matrix resin dan bahan pengisi yang diikat dengan baik oleh bahan coupling, sehingga jika sumber sinar mengenai permukaan komposit menyebabkan ikatan antara bahan-bahan yang terkandung dalam komposit semakin kuat dan meningkatkan sifat fisik dan mekanik dari komposit. ${ }^{5,6}$

Hasil uji kekerasan resin komposit pada kelompok kedua dan ketiga menunjukkan penyinaran dengan jarak 1 $\mathrm{mm}$ dan $2 \mathrm{~mm}$ memiliki nilai kekerasan yang cukup tinggi yakni 769,62 N/mm² dan $720,62 \mathrm{~N} / \mathrm{mm}^{2}$. Hasil penelitian ini sejalan dengan penelitian bahwa pada jarak 1-2 $\mathrm{mm}$ resin komposit masih dapat berpolimerasi dengan baik, sesuai pernyataan yang dikemukakan oleh Price di Universitas Leuven Belgia tahun 2000. Hasil penelitian ini juga sejalan dengan yang dikemukakan Anusavice bahwa resin komposit berpolimerasi dengan baik pada jarak penyinaran $1 \mathrm{~mm}$.,

Hasil uji kekerasan resin komposit pada kelompok keempat, kelima, dan keenam untuk jarak penyinaran 3-6 mm, nilai rata-rata kekerasan komposit semakin menurun tetapi masih dapat menahan tekanan kunyah maksimal manusia karena nilai kekerasan rata-rata pada jarak $6 \mathrm{~mm}$ sebesar 332,87 N/mm² sedangkan tekanan kunyah manusia sebesar $314 \mathrm{~N}$ (nilai kekerasan jarak $6 \mathrm{~mm}>$ tekanan kunyah ). Hal ini sedikit berbeda dengan yang dikemukakan oleh Neo dan Yap yang menyatakan bahwa jarak maksimal penyinaran resin komposit adalah $4 \mathrm{~mm}$. Perbedaan ini dapat terjadi karena jenis resin komposit yang digunakan oleh $\mathrm{Neo}$ dan Yap tidak disebutkan, sedangkan jenis resin komposit yang digunakan pada penelitian ini merupakan jenis nanohybrid yang merupakan jenis resin komposit terbaru. Resin komposit jenis nanohybrid memiliki kekerasan, ketahanan dan resisten terhadap fraktur lebih baik jika dibandingkan dengan jenis resin komposit lain karena pada komposit nanohybrid menggunakan bahan kaca dan silica yang lebih besar (0,4 micron) dan partikel nano (0,05 micron) dan sangat rapat antara satu dengan yang lain karena adanya pengelompokan nano (agglomerated nanocluster). ${ }^{4,8}$

Hasil penelitian untuk kelompok dengan jarak penyinaran $7 \mathrm{~mm}$ dan $8 \mathrm{~mm}$ memiliki nilai kekerasan 283,54 N/mm² dan $230,95 \mathrm{~N} / \mathrm{mm}^{2}$ sehingga tidak cukup untuk menahan tekanan kunyah manusia sebesar 314 N. Hal ini disebabkan semakin jauh jarak sumber sinar dengan permukaan resin komposit, sinar yang diterima komposit lebih sedikit dibandingkan dengan sinar yang diterima oleh kelompok dengan jarak penyinaran 0-6 mm sehingga aktifator yang terdapat didalam resin komposit tidak dapat mengaktifkan bahanbahan yang ada dalam resin komposit sehingga resin komposit tidak bisa berpolimerisasi dengan baik., 3,5

\section{SIMPULAN}

Dari hasil penelitian dan bahasan dapat disimpulkan bahwa jarak penyinaran terhadap resin komposit yaitu jenis nanohybrid sehingga resin komposit memiliki kekersan yang cukkup untuk menahan tekanan kunyah maksimal manusia yang berkisar pada jarak 0-6 mm.

\section{SARAN}

Diharapkan operator memperhatikan jarak penyinaran saat membuat restorasi menggunakan bahan resin komposit aktivasi sinar agar resin komposit memiliki kekerasan yang cukup untuk menahan tekanan kunyah maksimal manusia.

\section{DAFTAR PUSTAKA}

1. Kidd E, Bechal S. Dasar-dasar karies dan penanggulangannya. Jakarta: EGC, 1991; p. 171.

2. Theo M. Gambaran Kebocoran Tepi Tumpatan Pasca Restorasi Kom-posit pada Mahasiswa Program Studi 
Kedokteran Gigi Angkatan 20052007. Jurnal eG. 2013;1(2):115-20.

3. Mannapalill JJ. Basic Dental Materials 3rd ed. New Delhi: Jaypee Brothers, 2010; p. 26-30.

4. Morneburg TR, Porschel PA, Measurement of masticatory forces and implants load. The International Journal of Prosthodontic. 2002;15:207.

5. Anusavice KJ. Buku Ajar Ilmu Bahan Kedokteran Gigi. Jakarta: EGC, 2004: p. 228-43.

6. Braga RR, Ballester RY, Ferracane JL, Factors involved in the development of polymerization shrinkage stress in resin-composites: a systematic review. Dent Mater. 2005;21(10):962-70.

7. Craig RG, Powers JM, Wataha JC. Dental Materials. Properties and Manipulation. 8th ed. St. Louis, Missouri: Mosby Company, 2004; p. 64-85.

8. Garg N, Garg A. Textbook of Operative Dentistry. Boydell \& Brewer Ltd, 2010; p. 260.

9. Baum, Phillips, Lund, Buku Ajar Ilmu Konservasi Gigi. Jakarta: EGC, 1997; p. 254. 